\title{
Assessment of pain, acceptance of illness, adjustment to life with cancer, and coping strategies in colorectal cancer patients
}

\author{
Aleksandra I. Czerw ${ }^{1}$, Urszula Religioni ${ }^{1}$, Andrzej Deptała ${ }^{2,3}$, Bożena Walewska-Zielecka ${ }^{1}$ \\ ${ }^{1}$ Department of Public Health, Medical University of Warsaw, Warsaw, Poland \\ 2Division of Cancer Prevention, Medical University of Warsaw, Warsaw, Poland \\ ${ }^{3}$ Department of Oncology and Haematology, Central Clinical Hospital of the Ministry of Interior, Warsaw, Poland
}

Gastroenterology Rev 2016; 11 (2): 96-103

DOI: $10.5114 / p g .2015 .52561$

Key words: coping with pain, acceptance of illness.

Address for correspondence: Aleksandra I. Czerw MD, PhD, Department of Public Health, Medical University of Warsaw, 61 Zwirki i Wigury St, 08-456 Warsaw, Poland, phone: +48 501176 370, e-mail: ola_czerw@wp.pl

\begin{abstract}
Introduction: Every year more than 15,000 newly diagnosed cases of colorectal carcinoma are recorded in Poland.

Aim: The objective of the study was an assessment of coping strategies and pain management, acceptance of illness, and adjustment to cancer in patients diagnosed with colorectal carcinoma. The analysis was extended to include the effect of socioeconomic variables on the above-mentioned issues.

Material and methods: The study included 238 colorectal cancer patients treated on an outpatient basis at the Centre of Oncology, the Maria Skłodowska-Curie Institute in Warsaw in the year 2013. The questionnaire interview comprised demographic questions (socioeconomic variables) and the following four psychometric tests: BPCQ (Beliefs about Pain Control Questionnaire), CSQ (Coping Strategies Questionnaire), AIS questionnaire (Acceptance of Illness Scale), and the Mini-Mac scale (Mental Adjustment to Cancer).

Results: The source of pain control depends on the respondent's level of education. An increase in patient income was associated with a lower mean result in the "power of doctors" subscale. The coping self-statements and increased behavioural activity are the two most frequently selected strategies of coping with pain. The most commonly followed ways of mental adjustment to cancer in the study group were a fighting spirit (23.42) and positive re-evaluation (22.31).

Conclusions: Colorectal cancer patients believe that the greatest role in pain management is played by internal factors. The locus of pain control depends on the level of education. The study patients feature a constructive way of struggling with disease differentiated by the place of residence, professional status, and income.
\end{abstract}

\section{Introduction}

In Poland more than 15,000 new cases of colorectal carcinoma are registered every year [1]. The data from the National Register of Cancer (KRN) indicate that recently there has been a growth in the incidence and mortality in this type of carcinoma [2].

In Poland, the 5-year survival rate for colorectal cancer slightly exceeds $30 \%$. In contrast, said rate in Europe is $50 \%$, and in the United States - 80\% [1]. Early diagnosed colorectal cancer is very often curable. Early stage cancer diagnosis increases 5-year survival to as much as $90 \%$, whereas end-stage cancer diagnosis decreases the same rate to a mere $5 \%$ [3].
Colorectal cancer is the third most frequent carcinoma type in the world (10\% of all cancer types, after lung and breast cancer). Even though over $55 \%$ of cases are diagnosed in developed countries, these regions feature higher survival rates. Colorectal cancer occurs most often in Australia/New Zealand (incidence rate: 44.8/100,000 population for men and 32.2 for women), and least frequently in West Africa (4.5 and 3.8/100,000 population, respectively) [4].

The risk of colorectal cancer rises with age. $90 \%$ of diagnosed cases are recorded in patients above the age of 50, and the peak is observed past the age of 60 [5]. The risk is further elevated by a family history of col- 
orectal cancer, inflammatory bowel disease, and a low fibre diet typical of developed countries (few vegetables, abundance of fats and red meat) [6]. Colorectal cancer mortality rates in Poland are 18.9 for males and 10.2 for females (per 100,000 inhabitants) [7].

\section{Aim}

The objective of the study was an assessment of strategies of coping with and managing pain, disease acceptance, and adjustment to cancer in patients diagnosed with colorectal carcinoma. The analysis was extended to include the effect of socioeconomic variables (education, professional status, income, place of residence) and chemotherapy on the above-mentioned issues.

\section{Material and methods}

The study was based on 238 patients diagnosed with colorectal cancer and treated on an outpatient basis at the Centre of Oncology, the Maria Skłodowska-Curie Institute in Warsaw in the year 2013. The Paper and Pencil Interview (PAPI) technique was applied. The questionnaire interview comprised demographic questions (socioeconomic variables) and the following four psychometric tests: 1) Beliefs about Pain Control Questionnaire (BPCQ), designed to assess patients in pain; 2) Pain Coping Strategies Questionnaire (CSQ), used to evaluate patients suffering from pain; 3) Acceptance of Illness Scale (AIS), measuring patient adjustment to disease; 4) Mental Adjustment to Cancer (Mini-MAC), measuring the degree of mental adjustment to disease; 5) the study findings were then statistically analysed with the use of the Kruskal-Wallis and ANOVA tests.

\section{Statistical analysis}

The Mann-Whitney $U$ test was employed for the comparison of differences between the two study groups. The adopted statistical significance was set at $p<0.05$.

Test scores were correlated with the socioeconomic characteristics of the respondents: sex, education, professional status, place of residence, and net income-per-household-member, and with chemotherapy treatment in the past year.

\section{Results}

\section{Pain control}

The Beliefs about Pain Control Questionnaire (BPCQ), designed by S. Skevington, was developed to assess patients in pain [8]. It consists of 13 statements that form three subscales measuring the power of individual beliefs regarding pain management: internally (internal factors), through the power of doctors (powerful others), and by chance events [9].

Each of the statements is evaluated by the respondent on a scale from 1 to 6 , where 1 means "no, I completely disagree", and 6 - "yes, I completely agree". The total score for every BPCQ subscale is calculated separately on the basis of a sum of points awarded to each statement. The higher the score, the stronger the impact of a given subscale on pain management in a particular patient.

In the case of colorectal cancer patients, the highest score in the test was achieved by "internal factors" (17.36 with a standard deviation of 5.47), and the lowest by - "chance events" (15.72 with the standard deviation of 4.68) (Table I).

The socioeconomic variables that differentiated colorectal cancer patient results comprised: sex, education, net income-per-household-member, and professional status. Across all subscales of the BPCQ, males suffering from colorectal cancer scored slightly higher than females. However, only in the case of the powerful doctors the differences proved statistically significant $(p=0.027)$. The mean test score was 16.84 for men and 15.53 for women. The greatest impact of doctors on pain control was registered by elementary education patients, and the lowest - by higher education patients (14.74). Vocational and high-school graduates achieved corresponding mean results: 16.66 and 16.34 , respectively. With regards to the chance events subscale, the mean score was 16.89 in elementary education respondents, 16.91 in vocational education patients, slightly less, i.e. 15.80, in high-school education respondents, and just 13.60 in those with higher education (Table II). The results above proved to be statistically significant when classified by education. The higher the level of the respondent's education, the lesser the influence of doctors $(p=0.016)$ and chance events $(p=0.001)$ on pain management.

The means obtained in individual subscales of the questionnaire also decrease with an increase in respondents' income. Still, in the case of beliefs in the internal locus of pain control, no significant statistical difference was demonstrated in groups with different income. In the doctors' impact on pain management subscale, the mean result ranges from 17.44 in patients with PLN 300-600 of net income per household mem-

Table I. BPCQ test scores in colorectal cancer patients

\begin{tabular}{lcc} 
BPCQ subscale & Mean & Standard deviation \\
\hline Internal factors & 17.36 & 5.484 \\
\hline Power of doctors & 16.30 & 4.928 \\
\hline Chance events & 15.72 & 4.682
\end{tabular}


Table II. BPCQ test scores in colorectal cancer patients classified by level of education

\begin{tabular}{lcccc} 
BPCQ subscale & Education & $\boldsymbol{N}$ & Mean & Standard deviation \\
\hline Internal factors & Elementary & 27 & 18.44 & 5.444 \\
\cline { 2 - 5 } & Vocational & 65 & 18.29 & 4.993 \\
\cline { 2 - 5 } & High-school & 94 & 16.72 & 6.066 \\
\cline { 2 - 5 } & Higher & 52 & 16.96 & 4.715 \\
\hline Power of doctors & Total & 238 & 17.40 & 5.454 \\
\cline { 2 - 5 } & Elementary & 27 & 18.33 & 4.394 \\
\cline { 2 - 5 } & Vocational & 65 & 16.66 & 5.137 \\
\cline { 2 - 5 } & High-school & 93 & 16.34 & 4.478 \\
\cline { 2 - 5 } & Higher & 53 & 14.74 & 5.361 \\
\hline & Total & 238 & 16.30 & 4.938 \\
\hline & Elementary & 27 & 16.89 & 4.466 \\
\cline { 2 - 5 } & Vocational & 65 & 16.91 & 4.264 \\
\cline { 2 - 5 } & High-school & 93 & 15.80 & 4.320 \\
\cline { 2 - 5 } & Higher & 53 & 13.60 & 4.271 \\
\cline { 2 - 4 } & Total & 238 & 15.74 & 4.689
\end{tabular}

ber, 16.76 and 15.96 in respondents with an income of PLN 601-900 and 901-1200, respectively, and 14.27 in the case of respondents with the highest income $(p=0.033)$. In the subscale involving chance events having control over pain, a clear difference can be seen between the two groups with the lowest income, where mean scores achieved were 16.81 and 16.68, respectively, and the remaining two groups, with mean scores of 14.96 and 13.91 ( $p=0.002)$.

With regards to social status, in the powerful doctors' subscale the mean score of retired patients was 17.21, whereas that of the employed patients was 14.94. Furthermore, the retired respondents scored higher in the chance events subscale (mean value = 16.78) in comparison with the employed respondents (14.06). The above differences were demonstrated to be statistically significant ( $p=0.001$ for beliefs in doctors' power and $p<0.001$ for chance events).

\section{Strategies of coping with pain}

The Coping Strategies Questionnaire (CSQ), developed by Rosenstiel and Keefe [10], is used to evaluate patients complaining about pain. The questionnaire consists of 42 statements and is designed to evaluate patient strategies of coping with pain and to verify said strategies' effectiveness in pain reduction or control.

The questionnaire should be completed by each patient independently by evaluating individual statements using a scale ranging from 0 (never) to 6 (I always do that) (if the frequency of acting in a particular manner when in pain is determined), from 0 (I do not control it) to 6 (I totally control it) (if the degree of pain control is evaluated), and from 0 ( cannot reduce it at all) to 6 (I can reduce it completely) (if the rate of one's ability to reduce pain is estimated).

The methods of coping with pain reflect six cognitive strategies (diverting attention, reinterpreting pain sensations, catastrophising, ignoring pain, praying/ hoping, coping self statements) and one behavioural strategy (increased behavioural activity), which in turn form the following three components: cognitive coping, diverting attention and undertaking replacement activities, catastrophising, and hoping [11]. For each strategy, the calculated result is within the range 0 to 36 points. The higher the score, the greater the meaning attributed to a given factor in the process of coping with pain.

The top mean result for colorectal cancer respondents was attained by the coping self-statements subscale (mean $=21.86$ ), although an increased behavioural activity was assessed equally high (mean = 21.42). The catastrophising subscales scored the lowest $($ mean $=10.04)($ Table III).

Respondents with colon/rectum as the primary site ascribed various weights to, in particular, the praying/ hoping subscale as a consequence of their socioeconomic characteristics. The results obtained as part of said subscale were differentiated by: sex, education, net income-per-household-member, and professional status. When subdivided by sex, it turned out that women attributed more meaning to this strategy ( $p=0.015)$. Vocational and high-school level education patients obtained similar results, i.e. 22.97 and 20.55, respectively, 
while the mean score of university graduates was much lower, i.e. $15.60(p<0.001)$. Respondents in the two lowest income groups had mean scores of 21.80 and 23.49 , whereas for those in the top income groups it was as low as 18.52 and 14.48 ( $p<0.001)$. Retired patients thought the strategy was much more important (mean $=21.83)$ than the employed ones (17.51) $(p=0.001)$.

The sex of colorectal study subjects differentiated the scores in the increased behavioural activity subscale, too $(p=0.006)$. Women once more scored higher. Income differentiated the application of the diverting attention $(p=0.002)$ and catastrophising $(p=0.005)$ strategy. The recorded differences were pronounced, in particular between the two lowest income and two highest income groups. With regards to diverting attention the mean scores obtained were 20.15 and 22.85 for the lowest income groups, and 17.29 and 17.73 for the highest income groups. In the catastrophising subscale the results were 11.94 and 10.62 in the case of the former, and 9.63 and 6.66 in the case of the latter.

\section{Disease acceptance}

The AIS test includes eight statements regarding the negative consequences of poor health. Said consequences are grounded in accepting the limitations resulting from the disease, the feeling of dependence on others, decreased self-esteem, and a lack of self-sufficiency. Owing to its structure, the scale may be used to estimate the degree of acceptance in patients diagnosed with any condition. It is designed for use solely in currently ill adults. It is assumed that the higher the disease acceptance, the better the adjustment and the lower the feeling of mental discomfort. Each of the eight statements listed in the AIS can be graded on a scale from 1 to 5 . The study participant indicates one number which best describes his/her current status. Number 1 means: "I strongly agree", whereas number 5 stands for "I strongly disagree". Selecting 1 on the AIS scale shows poor adjustment to the disease, while choosing 5 - complete acceptance of the illness. An individual patient may score between 8 and 40 points, which will reflect the degree of illness acceptance. A low score means a lack of adjustment to the disease, no acceptance of one's condition, and strong mental discomfort. Any result near 40, on the other hand, will be indicative of acceptance of the disease and a lack of negative emotions related to the disease [12].

The mean score of patients with colorectal cancer in the AIS was 27.74 with a standard deviation of 8.36. The main socioeconomic factor differentiating the AIS scores in the study group was income $(p<0.001)$. We can observe a linear dependence between the net income per household member and the AIS score. In
Table III. CSQ test scores in colorectal cancer patients

\begin{tabular}{lcc} 
CSQ subscale & Mean & Standard deviation \\
\hline Diverting attention & 19.83 & 8.640 \\
\hline Catastrophising & 10.04 & 7.751 \\
\hline $\begin{array}{l}\text { Reinterpreting pain } \\
\text { sensations }\end{array}$ & 13.07 & 9.124 \\
\hline Ignoring pain & 17.00 & 9.203 \\
\hline $\begin{array}{l}\text { Praying/hoping } \\
\text { Coping self statements }\end{array}$ & 20.28 & 9.675 \\
\hline $\begin{array}{l}\text { Increased behavioural } \\
\text { activity }\end{array}$ & 21.86 & 9.432 \\
\hline
\end{tabular}

colorectal carcinoma respondents whose income per household member was below PLN 600, the mean test score was 23.11. The mean score exceeded 28.0 for the two consecutive income groups, whereas in the most affluent group of patients (PLN 1201-1500) it was 31.57 (Table IV).

Another factor differentiating the AIS scores in colorectal carcinoma patients was place of residence $(p=0.010)$. Respondents living in the countryside and small towns feature lower levels of illness acceptance when compared to inhabitants of larger cities (Table V).

Additionally, the level of acceptance of disease in the study group is diversified by undertaking chemotherapy in the past 12 months $(p=0.027)$. Patients who were not administered chemotherapy scored higher (28.88 compared to 26.73 for those who did not receive chemotherapy).

\section{Mental adjustment to disease}

The Mini-Mental Adjustment to Cancer (Mini-MAC) consists of 29 statements, and it measures four ways of coping with disease: anxious preoccupation, fighting spirit, helplessness-hopelessness, and positive re-evaluation; with anxious preoccupation and helplessness-hopelessness forming a part of the passive (destructive) style of coping with disease, and the other two referring to the active (constructive) way of coping. Each statement of the Mini-MAC is assessed by the respondent on a four-point scale ranging from 1 (definitely not) to 4 (definitely yes). The points in each strategy are calculated separately on the basis of the total scores obtained for particular statements, and the final results may be anything between 7 and 28 points. The higher the score, the more intense the behaviour patterns typical for a given coping strategy [13].

Colorectal cancer patients had the highest scores in the mini-MAC with regard to fighting spirit (23.42) 
Table IV. Disease acceptance vs. income in colorectal patients

\begin{tabular}{lccc} 
Net income per household member & N & Mean & Standard deviation \\
\hline Less than PLN 300 & 3 & 23.0000 & 10.53565 \\
\hline PLN 300-600 & 55 & 23.1111 & 6.91639 \\
\hline PLN 601-900 & 78 & 28.3896 & 7.96729 \\
\hline PLN 901-1200 & 56 & 28.8036 & 7.95994 \\
\hline PLN 1201-1500 & 44 & 31.5682 & 8.84070 \\
\hline PLN 1501-1800 & 2 & 21.5000 & 7.77817 \\
\hline Total & 238 & 27.7458 & 8.38711
\end{tabular}

Table V. Disease acceptance vs. place of residence in colorectal patients

\begin{tabular}{lccc} 
Place of residence & $\boldsymbol{N}$ & Mean & Standard deviation \\
\hline Countryside & 45 & 24.8000 & 9.35560 \\
\hline Town $<20000$ inhabitants & 30 & 26.7333 & 7.98677 \\
\hline Town $<50000$ inhabitants & 36 & 28.4444 & 7.09706 \\
\hline Town $<100000$ inhabitants & 27 & 25.1852 & 9.30276 \\
\hline City $<500000$ inhabitants & 16 & 29.6875 & 7.69172 \\
\hline City $>500000$ inhabitants & 84 & 29.8095 & 7.69208 \\
\hline Total & 238 & 27.7353 & 8.35558
\end{tabular}

and positive re-evaluation (22.31), and the lowest in the helplessness-hopelessness subscale (12.39) (Table VI).

Results obtained in the anxious preoccupation and positive re-evaluation subscales are differentiated by the place of residence. The mean score in the field of anxious preoccupation decreases along the size of the place one lives in (the mean score for the countryside is 16.93 and for cities above 500,000 inhabitants - 14.51, in this subscale) $(p=0.010)$. In the case of positive re-evaluation no statistically significant correlation was recorded $(p=0.028)$. The highest scores in this subclass were attained by respondents living in the countryside (23.04), and the lowest scores - by those living in towns of up to 100,000 inhabitants.

Table VI. Mini-Mac test scores in colorectal cancer patients

\begin{tabular}{lcc} 
Mini-Mac test subscale & Mean & Standard deviation \\
\hline Anxious preoccupation & 15.98 & 4.671 \\
\hline Fighting spirit & 23.42 & 3.641 \\
\hline Helplessness - hopelessness & 12.39 & 4.255 \\
\hline Positive re-evaluation & 22.31 & 2.828
\end{tabular}

As far as the positive re-evaluation subscale is concerned, the results of the mini-MAC were differentiated also by respondents' professional status $(p=0.008)$. The top mean scores in the subscale were obtained by students (23.00), and the bottom ones by homemakers (21.00).

The anxious preoccupation and helplessness-hopelessness subscales were varied by net income per family member ( $p=0.005$ and $p=0.004$, respectively) and the fact of undergoing chemotherapy in the last year ( $p=0.002$ and $p=0.004$, respectively). The highest values in the above areas are characteristic of patients of highest income. In the case of chemotherapy, treatment in the last 12 months resulted in an increase in mean scores in the above subclasses.

\section{Discussion}

Assessment of pain, in particular cancer pain, in a given population is very difficult. The International Association for the Study of Pain (IASP) distinguished two components of pain: sensory - related to a perception of pain, and emotional - described as an individual patient's reaction to a pain stimulus [14]. In view of the fact that the emotional component is subjective, pain frequency and intensity estimation is very demanding, 
as reflected by a lack of detailed data on the topic in subject literature [15].

The sensation of pain extends over three areas: somatic, mental, and behavioural [16]. When assessing cancer pain, in addition to standard descriptions of pain (such as mild or strong), there is a common use of the Visual Analogue Scale (VAS), allowing one to evaluate pain on a numerical scale [17]. Yet another thing doctors advise to draw special attention to, in addition to pain intensification, location source, time, and typical symptoms, are mental aspects of patient pain, such as anxiety, helplessness, fear, or resignation, which may play significant roles in the subjective perception of pain [18-20].

Our own research over colorectal patients indicates that with regards to pain management patients ascribe most weight to internal factors (mean $=17.36$ ) and least weight to chance events (mean $=15.72)$. The results of a study conducted with participation of patients with spondylalgia demonstrated corresponding results. The mean score obtained in the belief-in-internal-factors subscale turned out to be even higher than the mean value in our own study [21].

According to other analyses carried out with patients suffering from various conditions, the most crucial role in pain control was ascribed to doctors, and often to internal factors [22-24]. Many studies indicate that the sensation of pain is strongly correlated with a strategy of coping with pain selected by a patient, and it significantly mediates the health-related quality of life (HRQL) assessed by the patient [25-27]. The choice of strategy, in turn, is affected by individual convictions of patients regarding, amongst other things, one's self-efficiency. The feeling of power and ability causes one to select an active mode of behaviour, which is to fight pain [28].

With regards to the strategy of coping with pain described by CSQ, patients diagnosed with colorectal cancer assessed the coping self statements and increased behavioural activity the highest. The behavioural activity subscale was further differentiated by respondents' sex (women obtained higher results), as evidenced by the studies by Unruh et al. [29] and others. Moreover, Rolka demonstrated that in patients suffering from migraine another factor differentiating a selected coping strategy is age; pain is best coped with by women aged 31-40 years and men less than 30 and more than 50 years old [16].

Literature presents diverse results of the CSQ test obtained by various patient groups. For instance, in a study Rosenstiel and Keefe, chronically ill patients applied the praying/hoping and coping self-statement strategies most often [10]. Analogous results were dis- played by Andruszkiewicz et al., who analysed patients with degenerative join disease [30]. On the other hand, Juczyński indicates that patients selected the ignoring-pain strategy a lot [31].

An important aspect of cancer is the level of its acceptance by affected patients. Higher acceptance decreases intensification of negative emotions in the context of disease and facilitates acceptance of disease-induced limitations [32, 33].

The mean level of acceptance of illness measured with AIS in colorectal patients in our research was 27.74 , which is relatively high when compared to other groups of patients. Lower results than those attained by patients in our study were obtained by diabetic patients (mean $=24.81$ ), dialysed men (25.32), men post myocardial infarction (22.14), multiple sclerosis women (24.59), men in chronic pain (18.46) [34], and leukaemia patients [35]. Higher scores are typical of breast and uterine cervix cancer females (28.13) and chronically ill patients (28.08) [36]. Specialist literature shows that high level of disease acceptance positively affects control over symptoms and motivation to cope with pain [37-39].

Our own research findings denote a statistically significant relation between the level of illness acceptance amongst patients and net income per household member and chemotherapy. The other socioeconomic variables did not differentiate the study group. Rolka et al. [16], who studied patients with migraine, and Basinska and Andruszkiewicz [40], who analysed AIS in patients with Graves-Basedow disease and Hashimoto, also indicated no dependency of disease acceptance on sex or education.

In the subscales demonstrating mental adjustment to disease, measured with the mini-MAC, colorectal cancer patients had the highest scores in fighting spirit, and the lowest in helplessness-hopelessness. The patients feature an active style of coping with disease (the total of the fighting spirit and positive re-evaluation subscales is 45.73), which is thought to be an element significantly affecting longer survival, better quality of life, or reduction of symptoms [41, 42].

Juczyński, analysing the results of the mini-MAC in a similar group of patients, obtained a lower mean for the constructive style (36.56) and a markedly higher mean for the destructive style (39.94 in comparison with 28.37 in our research) [13]. A corresponding correlation was found in colorectal carcinoma patients in a study conducted by Kozak [43]. While in Juczyński's study a higher score in the constructive style of coping with disease was attributed to prostate cancer patients (mean $=46.20)$, in Kozak's analysis it was ascribed to female patients with reproductive organ cancer, where 
the fighting spirit strategy received 23.95 points, which is higher than that seen in the patients in our own study.

Some authors claim that the fighting spirit strategy contributes to patients' ability to see positive changes their disease introduces into their lives [44, 45]. What is more, van Laarhoven et al. noticed a positive effect of the same strategy on the quality of life of patients [46].

\section{Conclusions}

Patients ascribe the key role in pain management to internal factors. The rise in this subscale is noted along with the rise in patient education. The dominant strategies of coping with pain chosen by the study patients are coping self-statements and increased behavioural activity. The level of disease acceptance in colorectal patients depends on the level of net income per household member. The analysed patients predominantly feature a constructive style of coping with disease, although the style selected is differentiated by the place of residence, professional status, and net income per household member.

\section{Conflict of interest}

The authors declare no conflict of interest.

\section{References}

1. Gil J, Stembalska A, Łaczmańska I, Sąsiadek M. Sporadic colorectal cancer - factors modulating individual susceptibility to cancer. Współcz Onkol 2010; 14: 211-6.

2. National Registry of Cancer Cases, http://onkologia.org.pl/ nowotwory-zlosliwe-jelita-grubego-c18-21/, 19.09.2014.

3. National Cancer Combatting Program, http://www2. $m z$.gov.pl/wwwmz/index?mr $=q 101 \& m s \& m l=p l \& m i \& m x-$ $=0 \& m t \& m y=0 \& m a=5232,18.07 .2014$.

4. International Agency for Research on Cancer, Globocan 2012: Estimated Cancer Incidence, Mortality and Prevalence Worldwide in 2012, WHO 2012.

5. Society for colorectal cancer patients and promoting cancer prevention, http://www.europacolon.pl/?rak-jelita-grubego,3, 19.09.2014

6. American Cancer Society, Global Cancer, Facts \& Figures, Atlanta 2012: 13.

7. Polish Oncological Association, White Volume. Combatting colorectal and breast cancer in Poland in comparison with chosen European countries. The analysis of the resources of oncological care and the success determining conditions, Ośrodek Analiz Uniwersyteckich Sp. z o.o., Warszawa-Kraków, March 2012

8. Skevington SM. A standardised scale to measure beliefs about controlling pain (BPCQ): a preliminary study. Psychol Health 1990; 4: 221-32.

9. Juczyński J. Assessment tools in promotion and health psychology [Polish]. Pracownia testów psychologicznych, Warsaw 2009; 153
10. Rosenstiel AK, Keefe FJ. The use of cognitive doping strategies in chronic low back pain patients: relationship to patient characteristics and current adjustment. Pain 1983; 17: 33-44.

11. Juczyński J. Assessment tools in promotion and health psychology [Polish]. Pracownia testów psychologicznych, Warsaw 2009; 159.

12. Juczyński J. Assessment tools in promotion and health psychology [Polish]. Pracownia testów psychologicznych, Warsaw 2009; 165.

13. Juczyński Z. Assessment tools in promotion and health psychology [Polish]. Pracownia Testów Psychologicznych Polskiego Towarzystwa Psychologicznego, Warsaw 2001; 167-74.

14. International Association for the Study of Pain, IASP Taxonomyhttp://www.iasp-pain.org/Education/Content.aspx?ItemNumber $=1698 \&$ navltemNumber $=576 \#$ Pain (term: pain).

15. Hilgier M, Jarosz J. Treatment of pain in cancer patients - standards and guidelines [Polish]. Terapia 2006; 11: 35-41.

16. Rolka H, Krajewska-Kułak E, Kułak W, et al. Acceptance of illness and strategies in coping with pain as essential components of the quality of life dependent on health of patients with migraines. Initial report [Polish]. Problemy Pielęgniarstwa 2009; 17: 178-83.

17. NCCN Practice Guidelines for Cancer Pain, Benedetti C, Brock C, Cleeland et al., National Comprehensive Cancer Network Oncology (Williston Park) 2000; 14: 135-50.

18. Turk DC, Monarch ES, Williams AD. Cancer patients in pain: considerations for assessing the whole person. Hematol Oncol Clin North Am 2002; 16: 511-25.

19. Petrie KJ, Jago LA, Devcich DA. The role of illness perceptions in patients with medical conditions. Curr Opin Psychiatry 2007; 20: 163-7.

20. Linton SJ, Shaw WS. Impact of psychological factors in the experience of pain. Phys Ther 2011; 91: 700-11.

21. Juczyński Z. Assessment tools in promotion and health psychology [Polish]. Pracownia Testów Psychologicznych Polskiego Towarzystwa Psychologicznego, Warsaw 2001; 152.

22. Juczyński Z. Psychological indicators of adapting to cancer [Polish]. Psychoonkologia 1997; 1: 1-10.

23. Wiśniewska A, Szewczyk MT, Cwajda-Białasik J, et al. Beliefs on pain control in patients with chronic lower limb ischemia [Polish]. Piel Chirur Angiol 2009; 3: 113-21.

24. Misterska E, Jankowski R, Głowacki M. Chronic pain coping styles in patients with herniated lumbar discs and coexisting spondylotic changes treated surgically: considering clinical pain characteristics, degenerative changes, disability, mood disturbances, and beliefs about pain control. Med Sci Monit 2013; 19: 1211-20.

25. Verra ML, Angst F, Lehmann S, Aeschlimann A. Translation, cross-cultural adaptation, reliability, and validity of the German version of the Coping Strategies Questionnaire (CSQ-D). J Pain 2006; 7: 327-36.

26. Koleck M, Mazan JM, Rascle N, et al. Psychosocial factors and coping strategies as predictors of chronic evolution and quality of life in patients with low back pain: a prospective study. Eur J Pain 2006; 10: 1-11.

27. Jackson T, Pope L, Nagasaka T, et al. The impact of threateming information about pain on coping and pain tolerance. $\mathrm{Br}$ J Health Psychol 2005; 10: 441-51. 
28. Asqari A, Nicholas M. Pain self efficacy beliefs and pain behavior. A prospective study. Pain 2001; 94: 85-100.

29. Unruh A, Ritchie J, Merskey H. Does gender affect appraisal of pain and pain coping strategies? Clin J Pain 1999; 15: 31-40.

30. Andruszkiewicz A, Wróbel B, Marzec A, Kocięcka A. The strategies of coping with pain among patients with degenerative changes in the hip-joint [Polish]. Probl Piel 2008; 16: 237-40.

31. Juczyński Z. Perceived control versus the strategies of coping with chronic pain [Polish]. Sztuka Leczenia 2001; 7: 9-16.

32. Dijkstra A, Buunk AP, Tóth G, Jager N. Psychological adjustment to chronic illness: the role of prototype evaluation in acceptance of illness. J Appl Biobehav Res 2008; 12: 119-40.

33. Telford K, Kralik D, Koch T. Acceptance and denial: implications for people adapting to chronic illness. Literature review. J Adv Nurs 2006; 55: 457-64.

34. Juczyński Z. Assessment tools in promotion and health psychology [Polish]. Pracownia Testów Psychologicznych Polskiego Towarzystwa Psychologicznego, Warsaw 2001; 164.

35. Wiraszka G, Lelonek B. Functioning of leukemia patients versus acceptance of cancer [Polish]. Studia Medyczne 2008; 10: 21-6.

36. Felton BJ, Revenson TA, Hinrichsen GA. Stress and coping in the explanation of psychological adjustment among chronically ill adults. Soc Sci Med 1984; 18: 889-98.

37. Harrison T, Stuifbergen A, Adachi E, Becker H. Marriage, impairment, and acceptance in persons with multiple sclerosis. West J Nurs Res 2004; 26: 266-85.

38. Stuifbergen AK, Seraphine A, Roberts G. An explanatory model of health promotion and quality of life in chronic disabling conditions. Nurs Res 2000; 49: 122-9.

39. Martin LG. Adjusting to type 2 diabetes: the impact of illness cognitions on self management behavior and biological outcomes. Dissertation Abstracts International: Section B: The Sciences and Engineering 2012; 72: 5594.

40. Basinska MB, Andruszkiewicz A. Health locus of control in patients with Graves-Basedow disease and Hashimoto disease and their acceptance of ilness. Int J Endocrinol Metab 2012; 10: 537-42.

41. Pettingale KW. Doping and cancer prognosis. J Psychosom Res 1984; 28: 363-4.

42. Bussel V, Naus M. A longitudinal investigation of coping and posttraumatic growth in breast cancer survivors. J Psychosoc Oncol 2010; 28: 61-78.

43. Kozak G. Differentiation of strategies coping with cancer in patients with chosen malignant cancers [Polish]. Anestezjologia i Ratownictwo 2012; 6: 162-70.

44. Katz RC, Flasher L, Cacciapaglia H, Nelson S. The psychosocial impact of cancer and lupus: a cross validation study that extends the generality of "benefit-finding" in patients with chronic disease. J Behav Med 2001; 24: 561-71.

45. Urcuyo KR, Boyers AE, Carver CS, Antoni MH. Finding benefit in breast cancer: relations with personality, coping, and concurrent well-being. Psychology Health 2005; 20: 175-92.

46. van Laarhoven HW, Schilderman J, Bleijenberg G, et al. Coping, quality of life, depression, and hopelessness in cancer patients in a curative and palliative, end-of-life care setting. Cancer Nurs 2011; 34: 302-14.

Received: 2.02.2015

Accepted: 10.04.2015 